whereas TXAS and COX-2 expression was markedly induced by CSE and hypoxia, either individually or in combination in both hPASMCs and hPAECs. ET-1 expression was increased by CSE and hypoxia in hPAECs. Interestingly, ET-1 was upregulated by hypoxia, but reduced by CSE, with a net increase when both were combined in hPASMCs.

Conclusion These findings support our hypothesis that CS and hypoxia can cause an imbalance between excessive vasoconstrictors and deficient vasodilators in hPASMC and hPAECs. This imbalance may eventually lead to aberrant PASMC proliferation and vascular remodelling in COPD-associated PH. Further experiments are being conducted to confirm this by analysing vasoactive gene expression and mediator release in both hPASMCs and hPAECs. Our findings also pave the way for further studies on cellular functions and intervention drug effects.

\section{P47 HYPERCAPNIA IMPAIRS THE ABILITY OF MESENCHYMAL STEM CELLS TO PROMOTE DISTAL LUNG EPITHELIAL WOUND REPAIR IN ARDS}

NF Fergie, DF McAuley, CM O'Kane, AD Krasnodembskaya. Queen's University Belfast, Belfast, UK

\subsection{6/thoraxjnl-2017-210983.189}

Background Alveolar epithelial cell death and denudation of the basement membrane are hallmarks in the pathophysiology of Acute Respiratory Distress Syndrome (ARDS). Successful recovery requires basement membrane re-epithelialisation. While no pharmacological therapy exists for ARDS to date, Mesenchymal Stem Cells (MSCs) demonstrate promising therapeutic potential and are being tested in early-phase clinical trials. Heterogeneity of patients with ARDS is an obstacle for further development of an MSC-based therapy. While 20\% of patients with ARDS develop hypercapnia (high $\mathrm{CO}_{2}$ ) as a result of lung protective ventilation, the efficacy of MSCs has never been studied in this setting. We have previously found that transfer of functional mitochondria to surrounding cells is an important mechanism of the MSC therapeutic effect. The aims of this study therefore were to investigate the effect of MSCs on repair of the distal lung epithelium in normocapnia and hypercapnia in an in vitro model of ARDS, and to assess the role of mitochondrial transfer in mediating the MSC effect.

Methods Primary, human small airway epithelial cell (SAEC) monolayers were wounded in an in vitro scratch assay, stimulated with cytomix (IFN-gamma, I L-1 beta, TNF-alpha), and co-cultured with MSCs in normocapnia $\left(5 \% \mathrm{CO}_{2}\right)$ or hypercapnia $\left(15 \% \mathrm{CO}_{2}\right)$. Percentage wound closure was measured at 24 hour. SAEC proliferation was assessed by Ki67 staining. Mitochondrial transfer from MSCs to SAECs was assessed by flow cytometry using MitoTracker Green dye. MSC mitochondrial membrane potential was analysed by flow cytometry using JC-1. ATP production was measured by luminescent assay.

Results Epithelial wound closure was impaired by hypercapnia. MSCs promoted epithelial wound closure in the inflammatory setting in normocapnia via enhanced migration. This reparative capacity was lost in hypercapnia. Mitochondrial transfer from
MSCs to SAECs was observed to a similar extent in normocapnia and hypercapnia. However, hypercapnia attenuated mitochondrial membrane potential and ATP production in MSCs.

Conclusion While they promote epithelial wound repair in an inflammatory environment in normocapnia, MSCs lose this ability in hypercapnia. This suggests that their therapeutic efficacy may be lost in such an environment. An inhibitory effect of hypercapnia on MSC mitochondrial function may be at least partially responsible for this effect.

\section{P48 THE EFFECTS OF TGF-B AND IL-33 ON THE PRO- FIBROTIC ACTIVITY OF PRIMARY HUMAN LUNG FIBROBLASTS DURING THE DEVELOPMENT OF IPF}

${ }^{1} \mathrm{KE}$ Stephenson, ${ }^{2} \mathrm{CL}$ Overed-Sayer, ${ }^{1} \mathrm{AE}$ John, ${ }^{2} \mathrm{ES}$ Cohen, ${ }^{1} \mathrm{RG}$ Jenkins. ${ }^{1}$ University of Nottingham, Nottingham, UK; ${ }^{2}$ Medlmmune Ltd, Cambridge, UK

\subsection{6/thoraxjnl-2017-210983.190}

Introduction Idiopathic pulmonary fibrosis (IPF) is a debilitating interstitial lung disease with a poor prognosis and limited treatment options. It is a chronic, progressive, condition characterised by the excessive deposition of extracellular matrix by fibroblasts. Transforming growth factor- $\beta$ (TGF- $\beta$ ) is central to this process and is regarded as a key pro-fibrotic mediator in IPF. Recently, emerging evidence suggests that the cytokine interleukin-33 (IL-33) may also be important in the development of IPF. However, the cellular and molecular mechanisms by which IL-33 promotes fibrosis are unknown. In particular, whether TGF- $\beta$ and IL-33 have independent pro-fibrotic effects on fibroblasts remains unclear.

Methods Primary human lung fibroblasts (HLFs) from non-IPF and IPF patients were treated with either $2 \mathrm{ng} / \mathrm{ml}$ TGF- $\beta$ or $10 \mathrm{ng} / \mathrm{ml} \mathrm{IL-33.} \mathrm{The} \mathrm{levels} \mathrm{of} \mathrm{IL6} \mathrm{and} \mathrm{IL8} \mathrm{mRNA} \mathrm{were} \mathrm{used}$ as readouts of IL-33-mediated NF- $\kappa \beta$ activation whilst ACTA2 and COL1A1 mRNA were used as readouts of fibrosis. mRNA levels were measured by real-time quantitative reverse transcription polymerase chain reaction (qRT-PCR). Finally, the levels of IL-33, and its receptor ST2, were measured by qRTPCR to assess mRNA expression and western blotting to measure protein.

Results Stimulation with TGF- $\beta$ for 8 hours induced statistically significant increases in IL33 gene expression by both non-IPF and IPF HLFs. Moreover, TGF- $\beta$ stimulation of HLFs from patients with and without IPF induced IL-33 protein as assessed by immunoblotting. To assess the functional consequence of TGF-b induced IL-33 from fibroblasts, the effect of recombinant IL-33 on HLFs was determined. Increasing concentrations of IL-33 failed to stimulate IL6, IL8, ACTA2 and COL1A1 gene expression by either IPF or non-IPF fibroblasts. To understand the lack of IL-33 responsiveness in HLFs, ST2 levels were measured and neither ST2 mRNA or protein were detectable in IPF, or non-IPF, HLFs.

Conclusion TGF- $\beta$ increases IL-33 production by HLFs, however fibroblast-derived IL-33 does not act directly on fibrotic fibroblasts as they fail to express the receptor required for IL33 responsiveness. Therefore, the pro-fibrotic effects of IL-33 are likely mediated via alternative cell types. 
P49 THE EFFECTS OF ORAL COTRIMOXAZOLE UPON NEUTROPHIL AND MONOCYTE ACTIVATION IN PATIENTS WITH PULMONARY FIBROSIS AND HEALTHY CONTROLS; DOES THIS RELATE TO ITS ACTION IN IDIOPATHIC PULMONARY FIBROSIS?

VA Varney, B Smith, G Quirke, H Parnell, S Ratnatheepan, AS Bansal, A Nicholas. St Helier Hospital, Carshalton Surrey, UK

\subsection{6/thoraxjnl-2017-210983.191}

Sulfamethoxazole and dapsone share the same sulphonamide ring with similar antibacterial effects. Detailed studies of dapsone show extensive effects on the immune system with the reduced generation of oxygen free radicals (ROS) and inhibi-

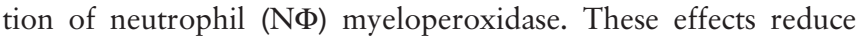
intra and extracellular ROS reducing endothelial damage, lipid peroxidation and apoptosis. The bacterial peptide $\mathrm{N}$-formyl-

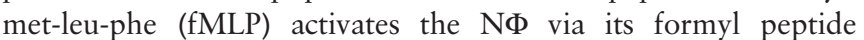
receptor (FPR) generating ROS much of which is extracellular. The FPR receptor also induces cell migration, granule secretion and lysosomal activation. Dapsone very significantly reduces fMLP activation of $\mathrm{N} \Phi$, giving anti-inflammatory effects. Interestingly phorbol 12-myristate 13-acetate (PMA), a well characterised activator of protein kinase $\mathrm{C}$ is less inhibited by dapsone. There are no comparable studies with cotrimoxazole despite its structural similarity. UK clinical studies of cotrimoxazole in Idiopathic pulmonary fibrosis (IPF), suggest protection against sudden severe exacerbations. Cotrimoxazole is thought to act via its anti-bacterial properties with data showing pathogen carriage in a third of new IPF cases. Oxidative stress is increased in IPF and limited studies show that peripheral monocyte $(\mathrm{M} \Phi)$ depletion via a charcoal column in IPF exacerbations has reduced the 30 day mortality. In fibrotic organ injury, recruitment of $\mathrm{M} \Phi$ appears critical and blocking $\mathrm{M} \Phi$ activation and recruitment arrests the fibrotic process. We have examined by flow cytometry the effects of oral cotri-

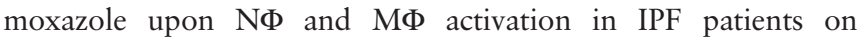

long-term treatment and healthy controls at baseline and after 1 week of cotrimoxazole. The commercial kit PHAGOBURST (Glycotope Biotechnology) was used, which allows quantitative determination of leucocyte oxidative burst in whole blood following stimulation by opsonized E Coli, PMA and fMLP.

Findings Despite the small numbers to date, similar to dapsone there is a significant blocking of oxidative burst to fMLP in $\mathrm{N} \Phi$ and $M \Phi$ pre- and post cotrimoxazole with a similar trend in IPF. There is also some reduction in PMA oxidative burst, but none to E.coli. The reduced M $\Phi$ stimulation may reflect the lower M $M$ bloods counts. If $N \Phi$ and $M \Phi$ ROS generation are reduced by cotrimoxazole, this may stabilise the disease process protecting against severe exacerbations.

\section{P50 LOCALISATION OF THE GLYCOLYTIC ISOZYME, PYRUVATE KINASE M2 IN THE LUNG OF IDIOPATHIC PULMONARY FIBROSIS}

S Tan, EJ Forty, PF Durrenberger, RJ McAnulty, RC Chambers, PF Mercer. Centre for Inflammation and Tissue Repair, UCL Respiratory, London, UK

\subsection{6/thoraxjnl-2017-210983.192}

Introduction Idiopathic pulmonary fibrosis (IPF) is the most common form of interstitial lung disease, with a poor prognosis and a lack of therapeutic options that halt disease progression. While the aetiology of IPF is unknown, dysregulated epithelial and mesenchymal response following persistent epithelial insult is thought to be critical in driving fibrosis. Recent evidence suggests that, akin to cancer, metabolic reprogramming may be important in driving many of these processes. In both cancer and fibrosis development, inducible expression of the pyruvate kinase isoform M2 (PKM2) represents an important adaptation for increasing the availability of glycolytic intermediates for biosynthesis and cell proliferation. Aim We aim to investigate the expression of PKM2 in relation to cell-specific markers in the IPF lung.

\begin{tabular}{|c|c|c|c|c|c|}
\hline $\begin{array}{l}\text { Neutrophils } \\
\text { Mean fluorescence }{ }^{*} \mathrm{SEM} \text { of stimulated } \\
\text { cells } \\
\text { (arbitrary units) }\end{array}$ & $\begin{array}{l}\text { Healthy controls } \\
\text { (HC) } \\
n=9 \\
\text { No treatments }\end{array}$ & $\begin{array}{l}\text { Healthy } \\
\text { controls } \\
\mathrm{n}=6 \text { post- } \\
\text { Cotrimoxazole } \\
7 \text { days } \\
\text { (960 mgBD) }\end{array}$ & $\begin{array}{l}\text { Paired } t \text { test } \\
+ \text { significance at the } 5 \% \\
\text { level } \\
\text { (pre- and post } \\
\text { Cotrimoxazole } n=6 \text { ) }\end{array}$ & $\begin{array}{l}\text { IPF on long-term } \\
\text { Cotrimoxazole } \\
\text { (mean treatment duration } 23 \text { months, } \\
\text { Cotrimoxazole } \\
\text { (960 mgBD) } \\
n=8\end{array}$ & $\begin{array}{l}\text { Mann Whitney U test } \\
\mathrm{HC} \text { versus IPF } \\
\text { +significance at the } 5 \% \\
\text { level }\end{array}$ \\
\hline Mean neutrophil blood count $10^{9} / l$ (SEM) & $3.32 \pm 0.24$ & $3.43 \pm 0.16$ & & $4.49 \pm 0.39$ & \\
\hline PMA N $\phi$ & $7014 \pm 1623$ & $5903 \pm 1503$ & $p=0.683$ & $3866 \pm 823$ & $p=0.117$ \\
\hline fMLP N $\phi$ & $989 \pm 242$ & $246 \pm 244$ & $p=0.015+$ & $448 \pm 407$ & $p=0.08$ \\
\hline $\mathrm{E}$ coli $\mathrm{N} \phi$ & $4417 \pm 447$ & $3302 \pm 815$ & $p=0.331$ & $3606 \pm 358$ & $p=0.189$ \\
\hline $\begin{array}{l}\text { Monocytes } \\
\text { Mean fluorescence }{ }^{*} \pm \text { SEM of stimulated } \\
\text { cells } \\
\text { (arbitrary units) }\end{array}$ & $\begin{array}{l}\text { Healthy controls } \\
\text { (HC) } \\
\text { No treatments } \\
\mathrm{n}=9\end{array}$ & $\begin{array}{l}\text { Healthy } \\
\text { controls } \\
\mathrm{n}=6 \\
\text { Cotrimoxazole } \\
7 \text { days } \\
(960 \mathrm{mgBD})\end{array}$ & $\begin{array}{l}\text { Paired } t \text { test } \\
+ \text { significance at the } 5 \% \\
\text { level } \\
\text { (pre- and post } \\
\text { Cotrimoxazole } n=6 \text { ) }\end{array}$ & $\begin{array}{l}\text { IPF on long-term } \\
\text { Cotrimoxazole } \\
\text { (mean treatment duration } 23 \text { months } \\
\text { Cotrimoxazole } \\
(960 \mathrm{mgBD}) \mathrm{n}=8\end{array}$ & $\begin{array}{l}\text { Mann Whitney U test } \\
\mathrm{HC} \text { versus IPF } \\
\text { +significance at the } 5 \% \\
\text { level }\end{array}$ \\
\hline Mean monocyte blood count $10^{9} / 1$ (SEM) & $0.55 \pm 0.06$ & $0.53 \pm 0.08$ & & $0.77 \pm 0.07$ & \\
\hline PMA M $\phi$ & $503 \pm 149$ & $236 \pm 109$ & $\mathrm{p}=0.99$ & $424 \pm 166$ & $p=0.541$ \\
\hline fMLP M $\phi$ & $1467 \pm 460$ & $38 \pm 24$ & $\mathrm{p}=0.05+$ & $1340 \pm 807$ & $p=0.276$ \\
\hline E coli M $\phi$ & $990 \pm 168$ & $787 \pm 136$ & $p=0.57$ & $808 \pm 144$ & $p=0.733$ \\
\hline
\end{tabular}

*fluorescine agent dihydrorhodamine123-maximum absorption 488-490 nm. 